\title{
What's Not Converging? \\ East Asia's Relative Performance in Income, Health and Education
}

\section{Charles Kenny ${ }^{\mathrm{i}}$}

\begin{abstract}
This paper discusses East Asia's performance in terms of per capita GDP growth rates over the past forty years and compares that performance to progress primarily on measures of health. It also compares the region to the rest of the World on a set of broader development measures. It looks at the evidence of East Asian regional and global convergence in health and education, alongside evidence from the region matching global evidence of a comparatively weak link between income growth and health and education growth. This finding is echoed by available within-country evidence from the region. The paper discusses what might be behind these results, suggesting the importance of a few simple supply-side interventions coupled with the spread of demand for health and education services as sufficient to drive quality of life convergence.
\end{abstract}

KEYWORDS: East Asia, convergence, economic growth, health, education 


\section{Executive Summary}

Using a range of measures of convergence, global performance on quality of life variables has been significantly stronger than performance on income in terms of convergence. This applies to measures of health, education, political and civil rights as well as access to infrastructure. For example, 80 percent of countries around the World for which we have data have seen infant mortality more than halve over the 1960-2005 period, compared to only 55 percent of countries which doubled income over that period. The figures for an East Asian sample are that 100 percent have seen infant mortality decline by 50 percent compared to 75 percent which have seen income double. This reflects the region's strong performance on both income growth and quality of life measures.

There was considerable economic growth across East Asia over 1960-2005 -almost a fivefold increase in the GDP per capita using a sample of countries with data over that entire period. There is also some evidence of convergence --faster growth in poorer countries. This evidence is not conclusive, and depends on the technique and data used. Nonetheless, East Asia's performance is far stronger on this measure than is performance for a global sample.

As to health outcomes, East Asian results mirror strongly those from a global sample. Infant survival, child survival and life expectancy all display strong signs of convergence at both the regional and global level. Infant survival for the East Asian sample has improved from 911 to 971 per thousand live births 1960-2005, while the standard deviation (a measure of variation in performance) has more than halved. Regarding education, once more East Asia appears to follow general global patterns. At the secondary level, the region improved its average score and rate of convergence even faster than the global sample. Average enrollment rates increased from 54 to 80 percent over the period 1991-2003. 
As suggested by the weaker evidence for income convergence than health convergence in East Asia and beyond, many other factors than income must lie behind the impressive gains we have seen in regional and global health. Richer countries in East Asia still see considerably better health outcomes than poor countries -a finding that matches the rest of the World. At the same time, globally, between 1870 and 1999, the income per capita associated with a given life expectancy has fallen tenfold. The United Kingdom reached Vietnam's current GDP per capita in the early Nineteenth Century. But Vietnam's literacy rate in 2000 is 95 percent compared to 69 percent in the UK in the early 1800 s, its current life expectancy is 69 compared to 41 in the UK when it had the same income, and its infant mortality is less than one quarter the UK's in the early 1800 s.

Over time, even comparatively positive estimates of the relationship between income growth on improvements in health suggest that between one quarter and one third of the change in health can be correlated with income change. Within the East Asia region, it is notable that China's greatest improvements in health were following the end of the Great Leap Forward but still prior to rapid economic growth. Indeed, within China, there is some evidence of health divergence over the recent past. Despite significant income growth, rural infant mortality rates have stagnated since 1981 at around 40 per 1,000 live births.

One factor behind this may be the collapse of China's Cooperative Medical System of insurance providing basic care which covered 90 percent of the rural population in the late 1970s, but fell apart after agriculture sector reform and a 65 percent decline in government subsidies. Access to simple and effective treatments of the kind previously provided by barefoot doctors in China appears to be one key to improved health.

Worldwide, the issue is increasingly one of the demand side of health --people are not using available technologies. In this regard, the impact of education -especially of mothers - has been found to be a significant determinant of health in numerous studies Consumer demand plus a basic (cheap) supply of health technologies appears to be sufficient to promote rapid global convergence in health outcomes. 


\section{Introduction: How Broad A Miracle?}

The phrase "East Asian Miracle" is perhaps one of the best known in development studies. The miracle is a topic in numerous academic articles -over 6,500 by one approximate measure ${ }^{\mathrm{ii}}$-- and a subject of lively debate as to causes and policy pointers. Capital fundamentalists war against technologists as to the role of accumulation versus total factor productivity (see Felipe, 1997 for a review). Dirigistes battle free traders as to lessons regarding the role of the state in development (see Yusuf and Stiglitz, 2001 for a review and compromise).

This focus should come as no surprise. GDP per capita growth rates averaged six percent in East Asia 1975-2000, by far the best performance of any region in the World. East Asia was the one region that upheld the promise of global income convergence -a number of countries grew significantly faster than the OECD average, suggesting the potential for rapid economic catch-up. This is exemplified by the fact that South Korea, only as rich as Ghana in 1960, is now itself a member of the OECD. Compare the Middle East and North Africa, for example, where regional per capita economic growth averaged about 0.5 percent over that same period. This may explain why the "Middle East Miracle" is a topic in perhaps one academic article, where it is used to describe a hoped-for future, not a dramatic performance in the past. ${ }^{\text {iii }}$

And yet, when it comes to the miracle of life rather than the miracle of riches, the Middle East and North Africa leads the global pack, noticeably ahead of East Asia. The region saw life expectancy increase by 21 years over the period 1962-2002, from an average of 48 to 69 . This performance $-\mathrm{a} 0.9$ percent annual growth rate-compares to 0.7 percent in the East Asian region over the same period. Indeed, East Asia also came behind South Asia in terms of growth in life expectancy, placing it near the middle of the developing region pack. On the bright side, most developing regions including East Asia saw life expectancy growth at a more rapid pace than OECD countries (at 0.3 percent), suggesting widespread global convergence in health even while very few countries were managing the same in income terms. 
This paper discusses East Asia's performance in terms of per capita GDP growth rates over the past forty years and compares that performance to progress primarily on measures of health. It also compares the region to the rest of the World on a set of broader development measures. It discusses the evidence of East Asian regional and global convergence in health and education, and looks at what might account for the far more widespread progress in measures of broad development even in countries where economic performance has been very poor indeed.

The analysis of East Asia's performance on quality of life measures in this paper will follow the framework of the global discussion referenced above (Kenny, 2005). But it is worth asking why we would expect convergence in quality of life measures. To use the example of health, in the presence of income convergence one could imagine that poorer countries would be able to expand health services provision comparatively rapidly, and (especially if one assumes a declining marginal return to expenditure on such services) this would lead to converging health outcomes. If we see health convergence absent such income convergence, some other force must be at work -perhaps a downward shift in the supply curve for health services and/or outcomes, or an upward shift in the demand curve. The later sections of this paper will discuss the relative importance of movement along the supply curve and downward shifts in the supply curve. It also touches on an increased demand for health services.

The paper opens with a brief discussion of the global picture of progress, where there is evidence of broad-based convergence across a range of development indicators with the notable exception of income. It then turns to the East Asian record, noting the more positive performance on income alongside considerable regional convergence (and dramatic growth) in health and education. East Asia performs perhaps a little better than would be expected given income performance on health measures. Having said that, the next section of the paper discusses evidence from the region matching global evidence of a comparatively weak link between income growth and health growth. This finding is 
echoed by available within-country evidence from the region. The penultimate section of the paper discusses what might be behind these results, and the last section concludes.

\section{The Global Picture of Convergence}

Kenny (2005) reports strong evidence of global convergence in quality of life variables even while similar evidence of income convergence is lacking. By a range of measures of convergence -weighted and unweighted coefficients of variation, bottom $20 \%$ divided by top $20 \%$ and beta convergence (an inverse correlation between starting values and growth) - performance on quality of life variables was significantly stronger than performance on income in terms of convergence. This applied to measures of health, education, political and civil rights as well as access to infrastructure. ${ }^{\text {iv }}$

The coefficient of variation (standard deviation divided by mean) of PPP GDP per capita for an unweighted global sample 1950-99 remained exactly the same at 0.85. Contrast this with life expectancy 1950-99 where the coefficient fell from 0.22 to 0.15 , primary enrollment from 1950 to 1990 where it fell 0.45 to 0.35 and the coefficient of variation on the ratio of female to male literacy $1970-2000$ which fell from 0.45 to 0.21 .

This quality of life convergence is not due to global stagnation in performance. Indeed, far more powerfully than with income, there is evidence of global progress in health outcomes. Coefficients of variation of growth in measures of infant mortality (at 0.43 over 1975-2000) are far lower than they are in income growth (at 1.59) (Kenny, 2005). 80 percent of countries for which we have data have seen infant mortality more than halve over the 1960-2005 period, compared to only 55 percent of countries which doubled income over that period. ${ }^{\mathrm{v}}$ The figures for an East Asian sample are that 100 percent have seen infant mortality decline by 50 percent compared to 75 percent which have seen income double. This reflects the region's strong performance on both income growth and quality of life measures which we discuss further below. But every region in the World has shared in health gains -in Sub-Saharan Africa, for example, life 
expectancy averaged 40 years in 1960, rising to 50 in 1992. It fell back to 47 in 1999 under the impact of the AIDS epidemic, but even so,this seven year gain over forty years is the same achieved in rich countries -and a far more impressive performance in percentage terms.

Before examining the East Asian case in more detail, it is worth making some caveats regarding both the quality of data and the quality of service provision in developing countries, including many in East Asia. Regarding the quality of data, whilst school enrollment measures tend to be broadly reliable, for example, the same cannot be said for mortality data in many countries. Often these data are based on extrapolation and forecast from samples with limited coverage. Furthermore, sources of error overlap between health variables as infant mortality is used to estimate under-five mortality and vice-versa while both are used to estimate life expectancy (McGuire, 2005).

At the same time, the dramatic changes in measured health improvement are large enough that they are robust to considerable error. Korenromp et al. (2004) suggest that reductions in under-five mortality rates of greater than 15 percent should be reliably detected by survey data even in fairly small countries. Over the period 1960-2005, global average under-five mortality has declined from 163 to 58 per 1,000 live births -a decline of around 64 percent.

Regarding the quality of outcomes, this is a particularly large concern for education variables, where enrollment and learning are two notably different things. Available direct measures, such as literacy, tend to reflect a very low standard of educational outcome. This is an unavoidable issue given the paucity of cross-country comparable data on more advanced educational outcomes, but should be borne in mind as we examine results. On health, life expectancy gains in developing countries have been driven by rapidly declining infant mortalities while the West has seen most of its gains from longer adult life. At the same time, it is not ethically straightforward as to which of these outcomes is 'higher quality' and, regardless, where we have data there is significant 
evidence of improvement in adult health in most developing countries as well (Kenny, 2007).

\section{East Asia's Performance: A Global and Regional Perspective}

Table 1 reports on evidence of convergence or divergence across a number of different indicators of the quality of life. These include income, fertility, doctors and hospitals per capita, literacy and school enrollment rates, immunization and sanitation access and a measure of gender equity -the percentage of parliamentarians who are women.

The table reports results on convergence for a global sample, a sample of East Asian countries and a sub-sample of larger (by population) East Asian economies. ${ }^{\text {vi }}$ The table reports on averages and standard deviations for variables at the start and end of the longest period over which there is sufficient data from the source (World Bank, 2007) to allow a meaningful comparison. The table reports on evidence of sigma convergence over that period -here defined as a decline in the coefficient of variation. The table also reports on beta convergence -here defined as a negative correlation between start values and growth over the period in the indicator. A negative sign is evidence of convergence, a positive sign of divergence, and a star by the sign suggests whether the result is statistically significant at a five percent level of probability according to a Student's T. The data is not weighted by population (such weighting in an East Asian sample means that Chinese data is overwhelmingly influential), and samples are not fixed-although this only leads to markedly different sample sizes at period start and end for a few variables.

For income, the data covers three different periods -1960-2005, 1980-2005 and 19902005. This is to ease comparison with other quality of life indicators for which we only have data over those different periods. It is worth noting that our broader East Asian sample over the longer period displays an average growth performance little better than the global average. This result would be markedly different if the sample was weighted 
by population size, as suggested by the 'large East Asia' column. The average East Asian's income is converging towards the income of citizens in wealthy countries.

What about within the region itself? All three time periods and both East Asian samples suggest regional beta convergence, in contrast to the global sample. In most cases, there is no evidence of sigma convergence in the region, although Table Two presents such evidence with a fixed sample. Table Two also suggests considerable economic growth across East Asia over the 1960-2005 period -almost a fivefold increase in the GDP per capita of the fixed sample. The fixed sample shows evidence of convergence, with a constantly declining coefficient of variation. It should be noted that a floating sample, including a number of countries in later periods that do not have data for early periods, still suggests growth, but does not suggest convergence, with a rising coefficient of variation in the period 1980-2005. Given that it is likely to be poorer countries who have more limited historical data on income, it may be that the truth regarding income convergence rests somewhere between the two measures. In short, evidence of income convergence is stronger at the East Asian regional than the global sample, but it is still not overwhelming.

As to health outcomes, regional results mirror strongly those from a global sample. Infant survival, child survival and life expectancy all display strong signs of convergence at both the regional and global level (although we should not take this as three independent pieces of evidence in favor of health convergence). ${ }^{\text {vii }}$ Take infant survival -for the East Asian sample, this has improved from 911 to 971 per thousand live births 1960-2005, while the standard deviation has more than halved.

Rates of progress in the global sample have been similar, if from a lower start, and slightly slower. Take life expectancy -for the global sample this increased from 54 to 67 1960-2005 while the standard deviation remained at twelve years. For East Asia, expectancy increased from 53 to 70 while the standard deviation fell from 11 to eight years. Table Two also suggests unambiguous evidence of health convergence and continued progress in both fixed and floating samples across every decade since 1960 and 
the period 1990-2005. It is also worth noting how much smaller are coefficients of variation in life expectancy than in income --0.11 compared to 1.03 in the fixed sample for 2005.

We have seen that East Asia's performance on health is not remarkable -with the Middle East and North Africa as well as South Asia seeing more rapid growth. Nonetheless, the region has performed strongly. For the nine East Asian countries for which we have data, ${ }^{\text {viii }}$ Figure 1 reports the average and standard deviation of life expectancy over time as compared to a global sample. This regional sample displays more rapid growth and more significant convergence than a global sample. Figure 2, using data from Cornia and Menchini (2005), displays the weighted standard deviation around the average of developing East Asia's infant mortality rates 1960-2000 (solid line). It also displays the average weighted standard deviation around the average mortality rate of other developing regions -Sub-Saharan Africa, Latin America, South Asia, Eastern Europe and Central Asia, Middle East and North Africa (dashed line). Weighted coefficients of variation across the developing world and the world as a whole have risen on this score, but this is because averages have fallen faster than standard deviations. The coefficient of variation in infant survival has fallen over this period -convergence towards 100 percent survival continues, and appears to be fairly rapid.

Regarding education, once more East Asia appears to follow general global patterns, if sometimes more rapidly and sometimes at a slightly slower pace depending on the measure. East Asia's performance in rolling out primary education prior to 1991 was strong enough that enrollment was close to universal, this is a factor behind slower progress in 'convergence' since then than found in a global sample. Similarly, literacy has been improving rapidly, but from a higher start and so perhaps unsurprisingly at a slower speed than global literacy. At the secondary level, however, the region improved its average score and rate of convergence even faster than the global sample. Average rates increased from 54 to 80 percent over the period 1991-2003. 
Looking at health determinants, the number of hospital beds per capita has actually fallen globally and regionally over the period 1960-2003, and in the region this has fostered a growing sigma divergence not noticeable in the global sample. The average decline and divergence in hospital beds, as compared to health outcomes, suggests something about the the importance of hospital beds as a determinant of overall country health, a topic we will return to. The number of phyisicians per capita has increased both globally and regionally, and there is strong evidence of convergence in the numbers. Having said that it is worth noting that East Asia performs reasonably poorly compared to the global sample both in average access and rates of convergence. East Asia has seen rapid growth and convergence in immunization, although starting from a higher level and slightly slower than the global sample.

One notable difference from global trends is East Asia's performance on access to a clean water source over the past fifteen years, which has been retrograde, and the region has fallen behind the global average in terms of this access. Finally, in terms of the fertility rate, the decline in an East Asian sample has been even more rapid than a global one -although as with the global sample the evidence is of beta convergence and sigma divergence.

This brief survey suggests that there may be some differences between East Asia and the rest of the World, particularly in the case of income growth and convergence. At the same time, in broader indicators of development progress, similarities outweigh differences. The region has shared in global progress towards widespread education and long life, performing a little better than global averages but not at particularly dramatic rates. This raises a question about the strength of the relationship between progress in income and progress in health in the region and the world as a whole.

\section{Income and Health -How Close the Relationship in East Asia?}


It is undoubted that 'wealthier is healthier', as Pritchett and Summers (1993) put it. On average, high income countries see average life expectancies 20 years longer than low income countries, and the same applies in East Asia. Japan's life expectancy of 82 is considerably higher than Cambodia's 57 years for example (data from World Bank, 2007). At the same time, globally, between 1870 and 1999, the income per capita associated with a given life expectancy has fallen tenfold. Countries with a GDP per capita of $\$ 1,000$ today have the life expectancy of a country with an income per capita of $\$ 10,000$ in 1870 . According to Maddison's latest data, ${ }^{\text {ix }}$ for sixteen large East Asian economies (in which category he includes India) income per capita has risen from $\$ 549$ to $\$ 3,608$ over that period -suggesting that, even in this fast-growing region, the passage of time has played a larger role in improvements in life expectancy than has income growth. This conclusion holds for countries home to at least 69 percent of the World's current population (Kenny, 2007).

Taking an example that involves East Asia, the United Kingdom reached Vietnam's current GDP per capita in the early Nineteenth Century. But Vietnam's literacy rate in 2000 is 95 percent compared to 69 percent in the UK in the early 1800 s, its current life expectancy is 69 compared to 41 in the UK when it had the same income, and its infant mortality is less than one quarter the UK's in the early 1800 s. Indeed, the child mortality level for the very richest of British subjects in the early Nineteenth Century was three times the average rate for Vietnam at the dawn of the Twenty-first Century (Kenny and Kenny, 2006).

Table 3 reports on the result of global regressions of life expectancy against the natural $\log$ of GDP per capita for a fixed sample over decades. Between 1960 and 2005, it is notable how much 'flatter' the relationship becomes, with the constant increasing from 0.48 to 15.27 while the coefficient on income declines. What this means in terms of global health outcomes is suggested by the last two columns which report on the expected life expectancy of a country as rich as China in 1960 (with a per capita GDP reported as $\$ 105)$ or Japan in 2005 (\$39,000). If China had seen no growth $1960-2005$, one would still have expected its life expectancy to grow from 36 to 46 based on this regression. If 
Japan was a rich in 1960 as it is today, one would have expected its life expectancy to rise only three years over that period. At the same time, it is also worth noting that health gains for poor countries appear to have been heavily concentrated in earlier decades, with the predicted change in life expectancy for a stagnant China of perhaps one year 19802005 (compared to four years for a country that stayed as rich as Japan in 2005 over that period).

Based on the regressions in Table 3, Figure 3 displays the variation of a sub-sample of countries in East Asia from predicted life expectancies given their income over the period 1960-2005. As can be seen, the majority of these countries actually follow the expected pattern quite closely -they are within ten percent of predicted life expectancy given income for the entire period (ten percent is approximately equal to one half of the standard deviation of global life expectancy). Given the rapid income growth of the region, this suggests a reasonably strong performance on life expectancy. The largest exception to the pattern is China which, during the Great Leap Forward, saw both economic decline and widespread famine that will significantly influence both income and life expectancy estimates for 1960. Nonetheless, in the period after the Great Leap, while the economy remained stagnant, life expectancy improved dramatically, so that China's performance was considerably better than expected given its low income by 1970 -life expectancies were 40 percent longer than would be predicted from a cross-country regression. The period since then has seen life expectancy performance return to what might be expected given the country's (rapidly increasing) income. The timing of this transition -improved health preceding improved income-is one that we will return to.

Figure 4 presents actual as a percentage of predicted life expectancy for a larger number of East Asian countries in 1960 and 2005. As can be seen, the average East Asian country did better on health outcomes than might be expected in both 1960 and 2005 (actual levels are more than 100 percent of predicted levels). Japan and Singapore in 2005 are notable under-achievers while Vietnam, the Philippines and (still) China outperformed expected life expectancies by 10-20 percent -impressive given a global standard deviation which is around 20 percent of the mean. 
Having said that the region's performance on health looks slightly better than might be expected given its income performance, it is again important to note that, across the World and over time, health and income growth are in fact poorly correlated. Even comparatively positive estimates of the relationship between income growth on improvements in health suggest that only between one quarter and one third of the change in health can be correlated with income change over time (Pritchett and Summers, 1993, Birchenall, 2007). Of course, even this level of correlation does not prove causation, with significant evidence of a health impact on economic growth (Chakrabborty et. al., 2005, Zhang and Zhang, 2005). Overall, there is no significant correlation between life expectancy growth and income growth for a small sample of countries 1913-2000 or for a larger global sample 1975-2000 -and only a weak link for child and infant mortality. These results are robust to choices regarding data quality and source and including initial values of variables or restricting samples to developing countries (Kenny, 2007).

Figure 5 displays a similar outcome for an East Asian sample regarding income and life expectancy growth 1960-2005. This result was also suggested by China's performance, where health growth predated income growth. Figure 6, using data from Cornia and Menchini (2005) displays data on infant mortality 1960-2000 for High Income Countries, China and the rest of East Asia. It is notable that China's greatest improvements in health were following the end of the Great Leap Forward but still prior to rapid economic growth, while the rest of East Asia actually improved its health performance as regional average growth rates began to decline in the 1980s and $90 \mathrm{~s}$.

\section{Within-Country Inequality in Health and Income in East Asia}

As is the case across countries, at any one time within countries there is a strong relationship between income and health outcomes, with poorer people seeing considerably worse health outcomes (Deaton, 2006). But added to evidence of a comparatively weak relationship over time between cross-country indicators of income 
and health, there is a weak relationship between income inequality and health outcomes across countries (Leigh and Jencks, 2007) and a weak relationship between changes in income inequality and health equality within countries.

Again, in the majority of the World's countries, including Japan and Indonesia, although with the exception of Malaysia, income inequality has increased over the recent past (Cornia and Menchini, 2005). Evidence from Demographic and Household survey data allows us to look at inequality of health outcomes by income quintile over the last few years. In the countries for which we have two DHS datapoints over time, relative gaps in infant mortality may have been rising in the majority of cases, but in the great majority of countries, relative gaps in infant survival have been declining (Cornia and Menchini, 2005). Looking at Indonesia, for example, the ratio of rural to urban infant mortality increased from 1.46 to 1.67 over the course of the period from the mid 1980s to mid $1990 \mathrm{~s}$, but the ratio of rural to urban infant survival increased from 0.974 to $0.978 .{ }^{\mathrm{x}}$

Again, in Japan, despite growing income inequality, there is evidence of greater equality in health outcomes. Fukuda et. al. (2004) report that variation in age-adjusted mortality rates across 3,340 municipalities in Japan declined slightly between the periods 1973-77 and 1993-98, with the high-mortality quintile for males seeing 24.0 percent more deaths than the low mortality quintile in the earlier period declining slightly to 20.3 in the later period while the figures for women were 20.9 and 20.1, respectively. ${ }^{\mathrm{xi}}$

There is some evidence of unambiguous health divergence in China, however. Liu et. al. (1999) find that infant mortality in urban areas of China was considerably lower than rural mortality rates in 1981. Since then, urban areas have seen mortality declined further to less than 15 per 1,000 live births whilst rural infant mortality rates have stagnated at around 40 per 1,000 live births. Over the same period, urban income rose approximately sixfold while rural incomes, whilst seeing considerable increase, could not match this growth rate. In short, despite significant income growth in rural areas, and health improvement nationally, rural areas saw health stagnation. (There is also evidence 
widening educational inequalities, although rural areas are seeing improvements -see Lee, 2006).

\section{If Not (Only) Income, What is Determining East Asian Health Outcomes?}

Given considerably rising incomes in rural areas of China, what accounts for the stagnation of health indicators? One factor may be the collapse of the Cooperative Medical System of insurance providing basic care which covered 90 percent of the rural population in the late 1970s, but fell apart after agriculture sector reform and a 65 percent decline in government subsidies. By 1993, only 21 percent of China's population had insurance. The number of active primary health care workers in rural areas declined 36 percent 1980-89 (Liu et. al., 1999).

Access to simple and effective treatments of the kind previously provided by barefoot doctors in China appears to be one key to improved health. In developing countries, the three diseases of diarrhea, pneumonia and malaria are the major causes of death between the second week and fifth year of life. All three can be easily prevented and/or treated using better hygiene, vector control, rehydration, antimalarials and antibiotics (Boone and Zhan, 2006). It is extension of access to these basic treatments that lies behind global improvements in health. Over the recent past, there has been a considerable global convergence in the percentage of children vaccinated against diphtheria, polio, tetanus and measles, for example (Comin et. al. 2006). Indeed, even in poor countries, diseases of the rich have now become big killers as diseases of the poor are conquered. In those countries, more people die each year from high blood pressure, high cholesterol, obesity, physical inactivity, tobacco, alcohol, and illicit drug consumption than die of malnutrition, indoor smoke, unsafe water and poor sanitation (Kenny and Kenny, 2006). xii $^{\text {. }}$

A basic package of rural primary health services only cost between around $\$ 3$ and $\$ 6$ in a recent survey (Loevinsohn and Harding, 2005), jibing with a national level estimate by 
Easterlin (1995) suggesting that the cost requirements of major improvements in life expectancy are no more than 2 percent of GDP even in the poorest countries. A similar finding applies to education, where universal primary education appears to be an affordable good at very low levels of income (given this, it is not surprising that growth in primary enrollments over the last thirty years is also unconnected with GDP per capita growth -see Kenny, 2007).

We can see that it is these cheap interventions that play the largest role in improving outcomes because direct measures of comparably expensive health inputs -hospital beds per capita, doctors per capita - do not appear to be robustly associated with health outcomes, as suggested by earlier evidence regarding a falling number of beds per capita worldwide (see also Ranis and Stewart, 2001, Filmer, Hamner and Pritchett, 1997). To use a regional example, the United States spends twice the OECD average on healthcare -13 percent. It is four times richer than Malaysia on a per capita basis. And yet its reported infant mortality rate is the same. Malaysia has a strong network of rural midwives with access to drugs and equipment which has not only reduced infant mortality to similar levels as the US (about 7 per 1,000 live births), but reduced maternal mortality to 19 per 100,000 live births compared to 17 per 100,000 in the US (Kenny and Kenny, 2006). ${ }^{\text {iii }}$

In many countries, the demand side of health care is a particularly significant issue -people are not using available technologies. For example, Dearden et. al. (2003) use data from DHS to find that educated mothers exposed to media, as well as those living in communities where others know the correct response, are all more likely to know how to treat diarrhea events and thereby save lives. The impact of education -especially of mothers - has been found to be a significant determinant of health in numerous studies (see Kenny, 2007, for a listing).

Consumer demand plus a basic (cheap) supply of health technologies appears to be sufficient to promote rapid global convergence in health outcomes, then. It is worth noting here that Filmer (2004) and Clemens (2004) between them find similar results 
regarding education -strong evidence of global convergence in which demand is a key factor. This is not to say that income is irrelevant, but it is clearly only one fact amongst many that determines outcomes in measures of the broader quality of life.

\section{Conclusion}

The picture for East Asia regarding income growth and convergence is considerably more positive than it is for a global sample. Nonetheless, there are still many poor people in the region who are falling further behind wealthier parts of the region and the World. Regarding health and education outcomes, progress has been more nearly universal. East Asia has partaken in the global improvement in quality of life, one that has also reduced global and regional disparities. This has occurred because of the strong outcomes achievable at low incomes where the basic supply of services (and demand for those services) is in place.

At the same time, the global convergence in health outcomes has slowed in recent decades, and East Asia has not been immune. In particular, it is a considerable tragedy that China, despite rapidly growing wealth, was unable to maintain the level of supply of basic health services in rural areas in the 1990s, leading to a stagnation in health outcomes. It should be a focus of the region's and the World's policymakers to ensure countries return to the rapid path towards quality of life convergence seen in the $1960 \mathrm{~s}$ and 1970s.

Such a policy focus would have two elements - progress towards universal access to basic health services and ensuring ubiquitous knowledge regarding the nature of disease and effective responses. A number of approaches - conditional cash transfers covering both basic service providers and parents, basic education for girls - have shown their efficacy as tools to expand both the supply of and demand for basic health treatments in this regard. A broader focus on the quality of life in the region and developing world would suggest a considerable expansion in support for such programs. 


\begin{tabular}{ccccc} 
Global & East Asia & \multicolumn{2}{c}{ Large East Asia } \\
Start End Start End Start End
\end{tabular}

Immunization, DPT (\% of children ages 12-23 months)

$$
1980 \text { to } 2005
$$

Average
Standard Deviation
Coeff. of Variation
Sigma Convergence
Beta Convergence
Observations

$\begin{array}{rrrrrr}48 & 86 & 53 & 82 & 50 & 84 \\ 29 & 15 & 22 & 15 & 23 & 15 \\ 0.62 & 0.18 & 0.43 & 0.18 & 0.47 & 0.18 \\ & \text { TRUE } & & \text { TRUE } & & \text { TRUE } \\ & -{ }^{*} & & -*^{*} & & - \\ 101 & 190 & 17 & 29 & 10 & 16\end{array}$ *

Improved water source (\% of population with access) 1990 to 2004

\begin{abstract}
Average
Standard Deviation

Coeff. of Variation

Sigma Convergence

Beta Convergence

Observations
\end{abstract}

$\begin{array}{rrrrrr}79 & 82 & 83 & 81 & 80 & 80 \\ 22 & 19 & 19 & 20 & 21 & 21 \\ 0.28 & 0.23 & 0.23 & 0.25 & 0.26 & 0.27 \\ & \text { TRUE } & & \text { FALSE } & & \text { FALSE } \\ & -{ }^{*} & & -*^{*} & & - \\ 146 & 177 & 23 & 29 & 13 & 16\end{array}$

Life expectancy at birth, total (years) 1960 to 2005
Average
Standard Deviation
Coeff. of Variation
Sigma Convergence
Beta Convergence
Observations

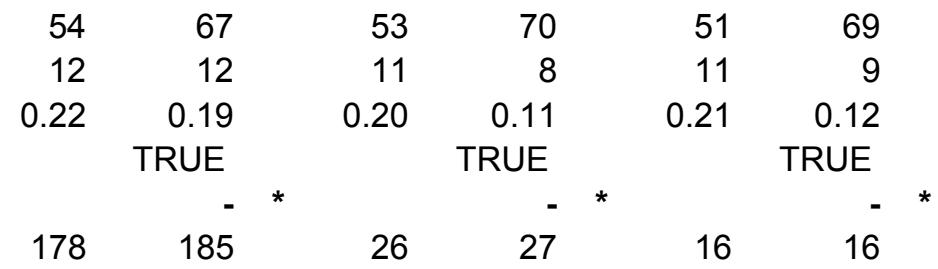

Literacy rate, adult total (\% of people ages 15 and above) 1990 to 2006

Average
Standard Deviation
Coeff. of Variation
Sigma Convergence
Beta Convergence
Observations

$\begin{array}{rr}71 & 80 \\ 23 & 21 \\ 0.33 & 0.26 \\ & \text { TRUE } \\ & - \\ 121 & 116\end{array}$

79

14

87

75

85

0.17

12

0.14

TRUE

0.18

12

0.14

TRUE

12

9

12

Survival Rate, infant (per 1,000 live births)

$$
1960 \text { to } 2005
$$

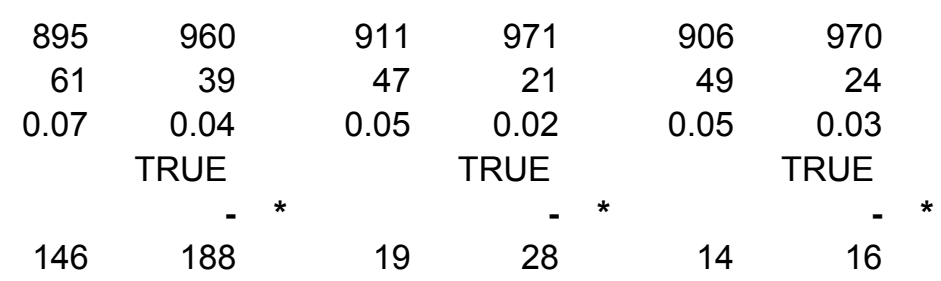




\begin{tabular}{cccc} 
Global & East Asia & \multicolumn{2}{c}{ Large East Asia } \\
Start End Start End Start End
\end{tabular}

Survival Rate, under-five (per 1,000 live births) 1960 to 2005

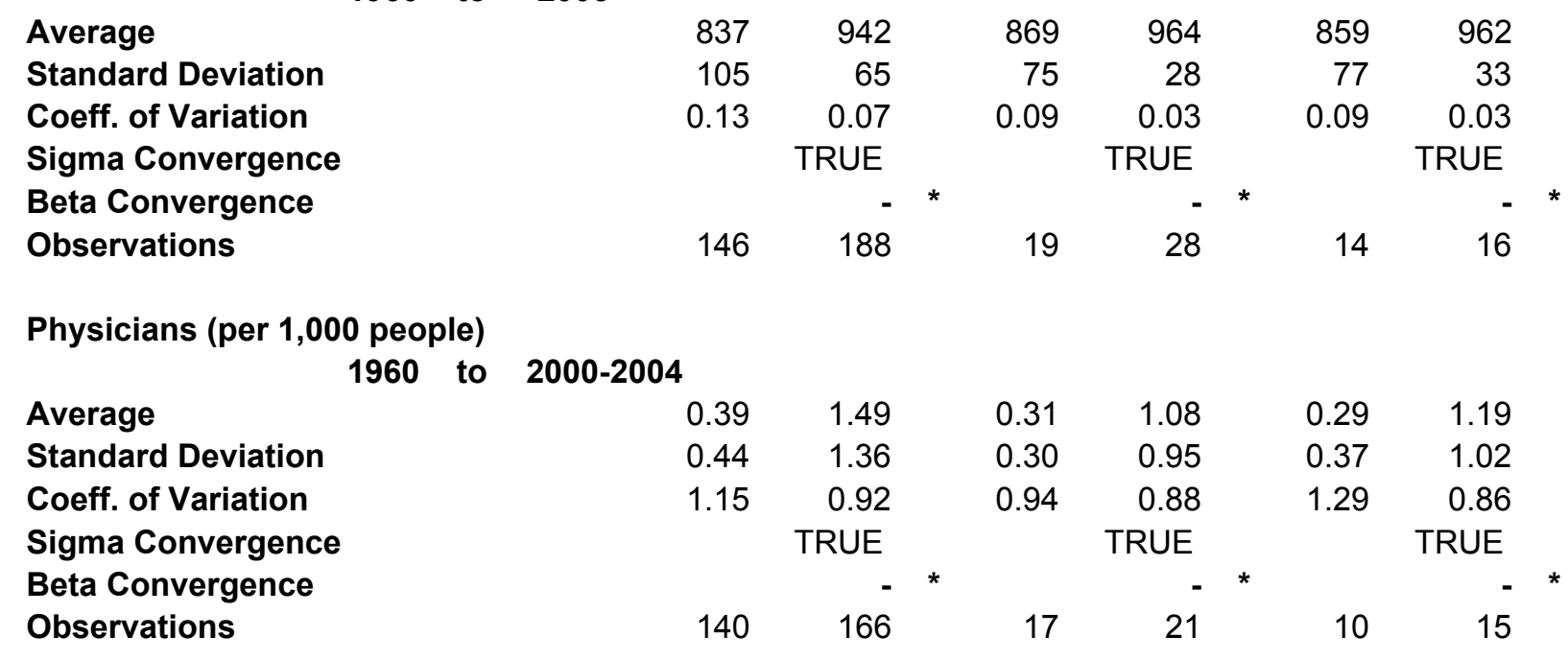

Proportion of seats held by women in national parliament (\%) 1990 to 2006

\begin{abstract}
Average
Standard Deviation

Coeff. of Variation

Sigma Convergence

Beta Convergence

Observations
\end{abstract}

School enrollment, primary (\% gross)

1991 to 2005

Average

Standard Deviation

Coeff. of Variation

Sigma Convergence

Beta Convergence

Observations

School enrollment, secondary (\% gross)

1991 to 2004

$\begin{array}{rrrrrr}10 & 16 & 8 & 12 & 10 & 15 \\ 9 & 10 & 8 & 10 & 8 & 8 \\ 0.88 & 0.65 & 1.07 & 0.78 & 0.87 & 0.52 \\ & \text { TRUE } & & \text { TRUE } & & \text { TRUE } \\ & -*^{*} & & -*^{*} & & -{ }^{*} \\ 135 & 179 & 20 & 25 & 14 & 14\end{array}$

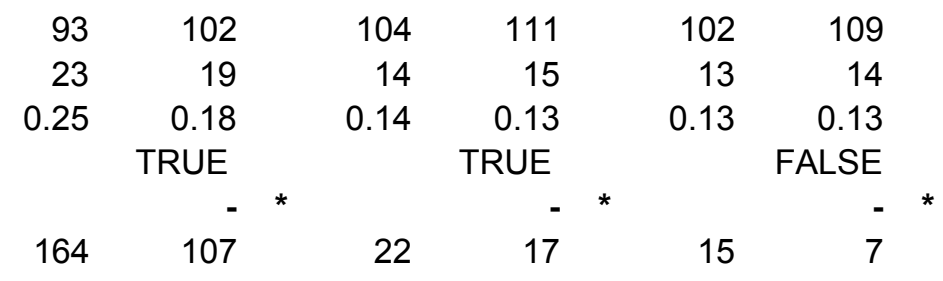

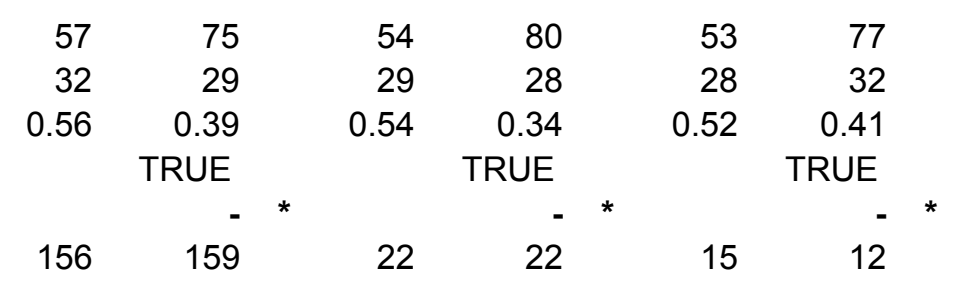


Table 2: Convergence within East Asia: Fixed and Floating Samples

Fixed Sample GDP per Capita

Average

Coefficient of

Variation

Life Expectancy

Average

Coefficient of

Variation

Floating

Sample

GDP per Capita

Average

Coefficient of

Variation

Life Expectancy

Average

Coefficient of

Variation

Notes: fixed sample is 12 for

$\begin{array}{rrrrr}1960 & 1970 & 1980 & 1990 & 2005 \\ 2758 & 4613 & 6446 & 9001 & 13121 \\ 1.22 & 1.24 & 1.16 & 1.15 & 1.03 \\ 54 & 59 & 63 & 67 & 71 \\ 0.19 & 0.16 & 0.16 & 0.13 & 0.11\end{array}$

$2629 \quad 4450 \quad 6451 \quad 6700 \quad 7742$

$\begin{array}{lllll}1.23 & 1.18 & 1.15 & 1.23 & 1.41\end{array}$

$\begin{array}{lllll}54 & 59 & 63 & 67 & 71\end{array}$

$\begin{array}{lllll}0.19 & 0.16 & 0.15 & 0.12 & 0.11\end{array}$ GDP per capita, 30 for life expectancy. Floating sample is $13-$ 28 for GDP per capita, 30-33 for life expectancy. Source: WDI.

Table 3: Decadal Regressions of Life Expectancy Against Income 1960-2005

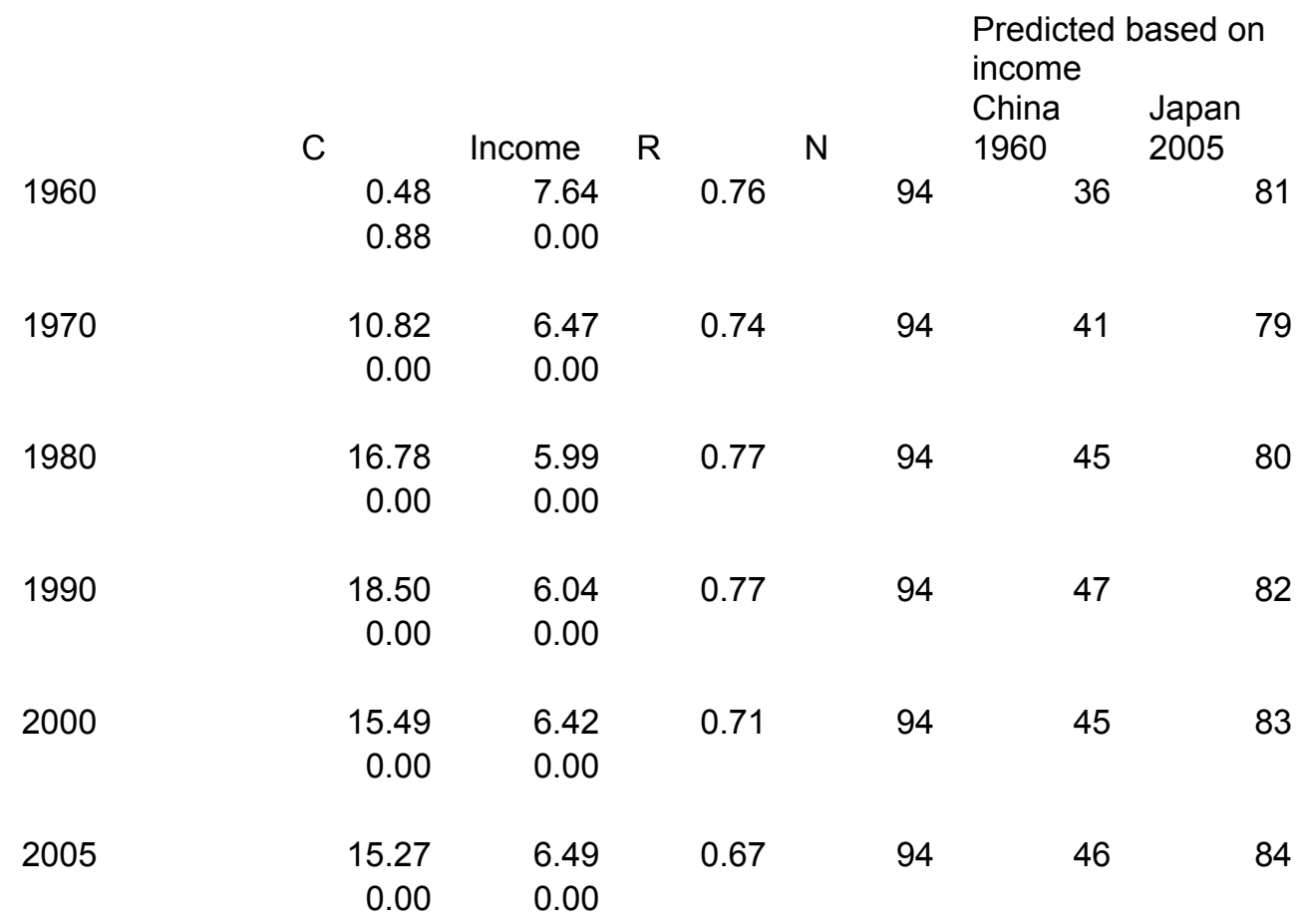

Notes: global sample, regression of life expectancy against log income. Last two columns use 1960 China and 2005 Japanese income values to estimate predicted life expectancy at the given date at those income levels. Source: WDI. 
Figure One: Average and Standard Deviation of Life Expectancy in East Asia (Dashed) and the World (Solid).

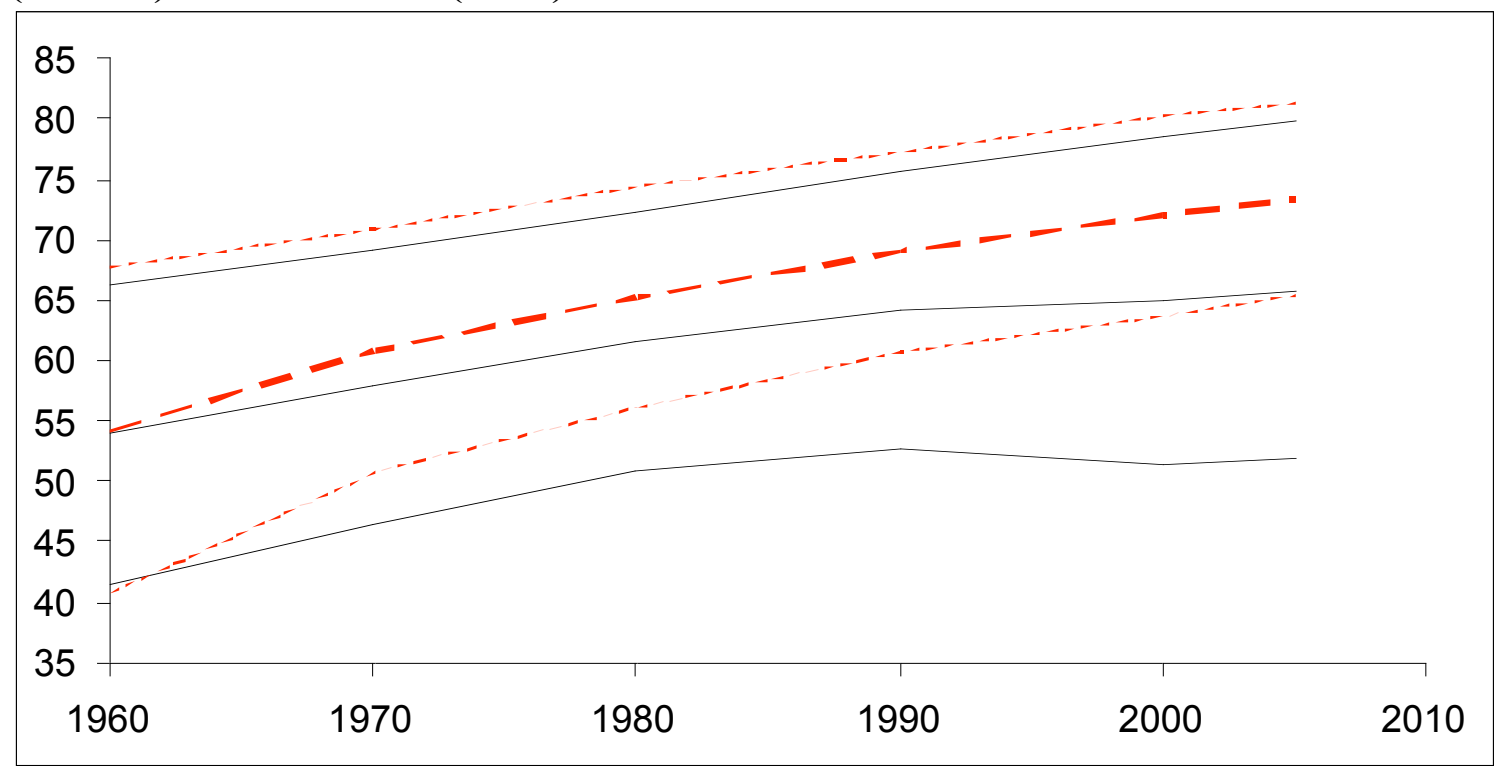

Figure 2: Weighted Standard Deviation Range of Infant Mortality Around Average, East Asia (Solid) and Average for Other Developing Country Regions (Dashed)

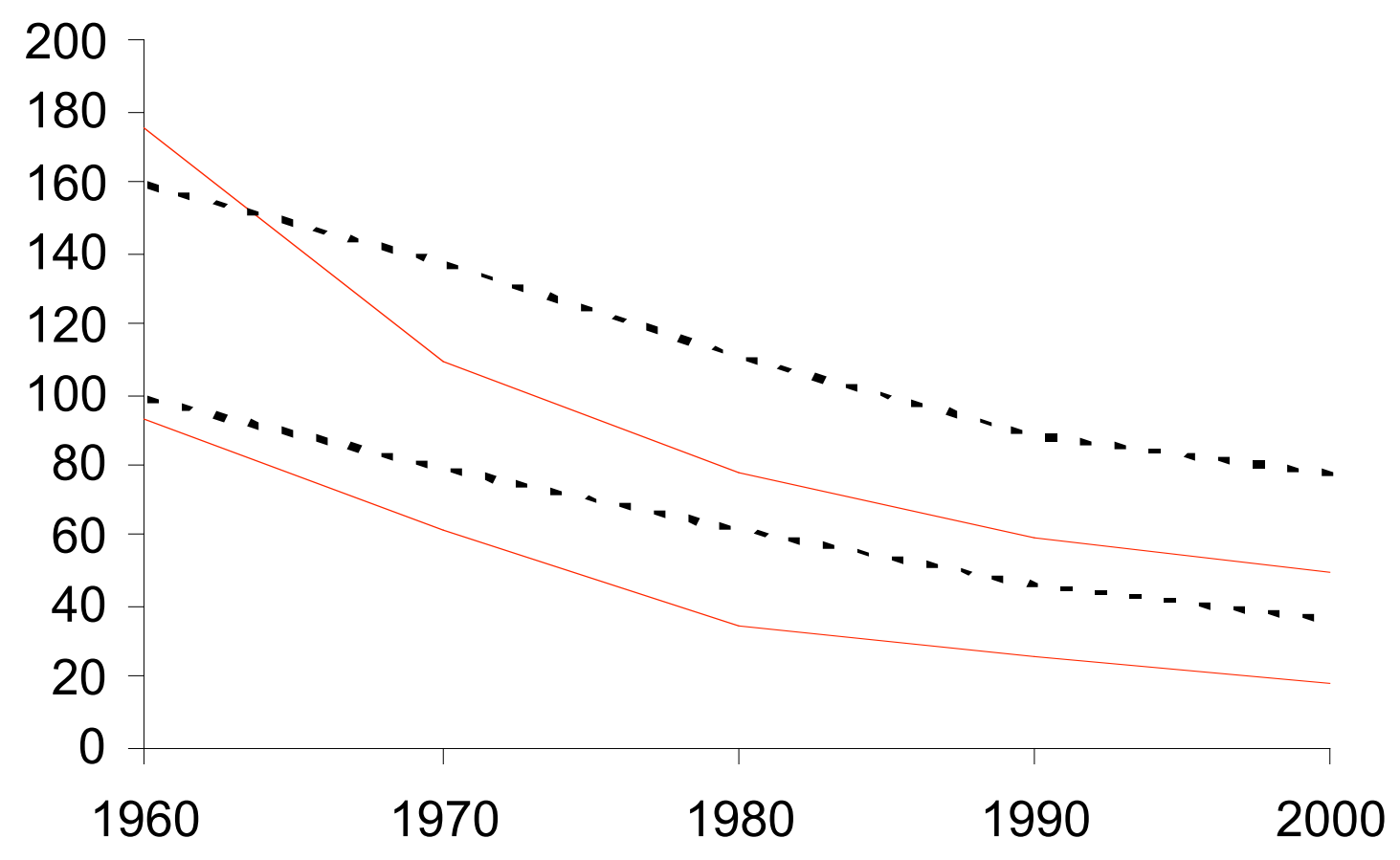


Figure 3: Actual Versus Predicted Life Expectancy in East Asia, 1960-2005

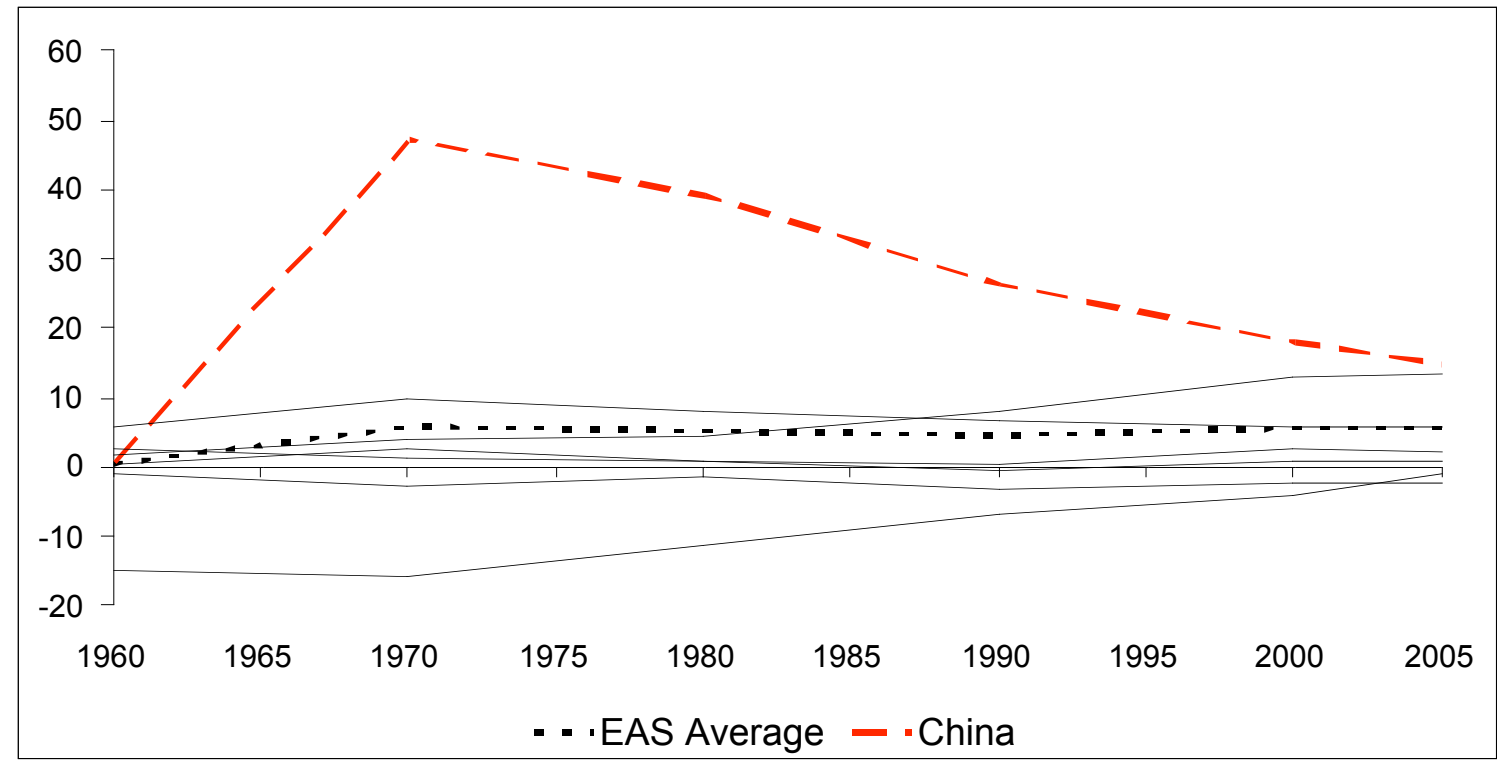

Note: solid black lines report results for Australia, Indonesia, Japan, Rep. Korea, Malaysia, New Zealand, Papua New Guinea and the Philippines 
Figure 4: Actual Life Expectancy as a Percentage of Predicted Based on Regression of Life Expectancy Versus Income

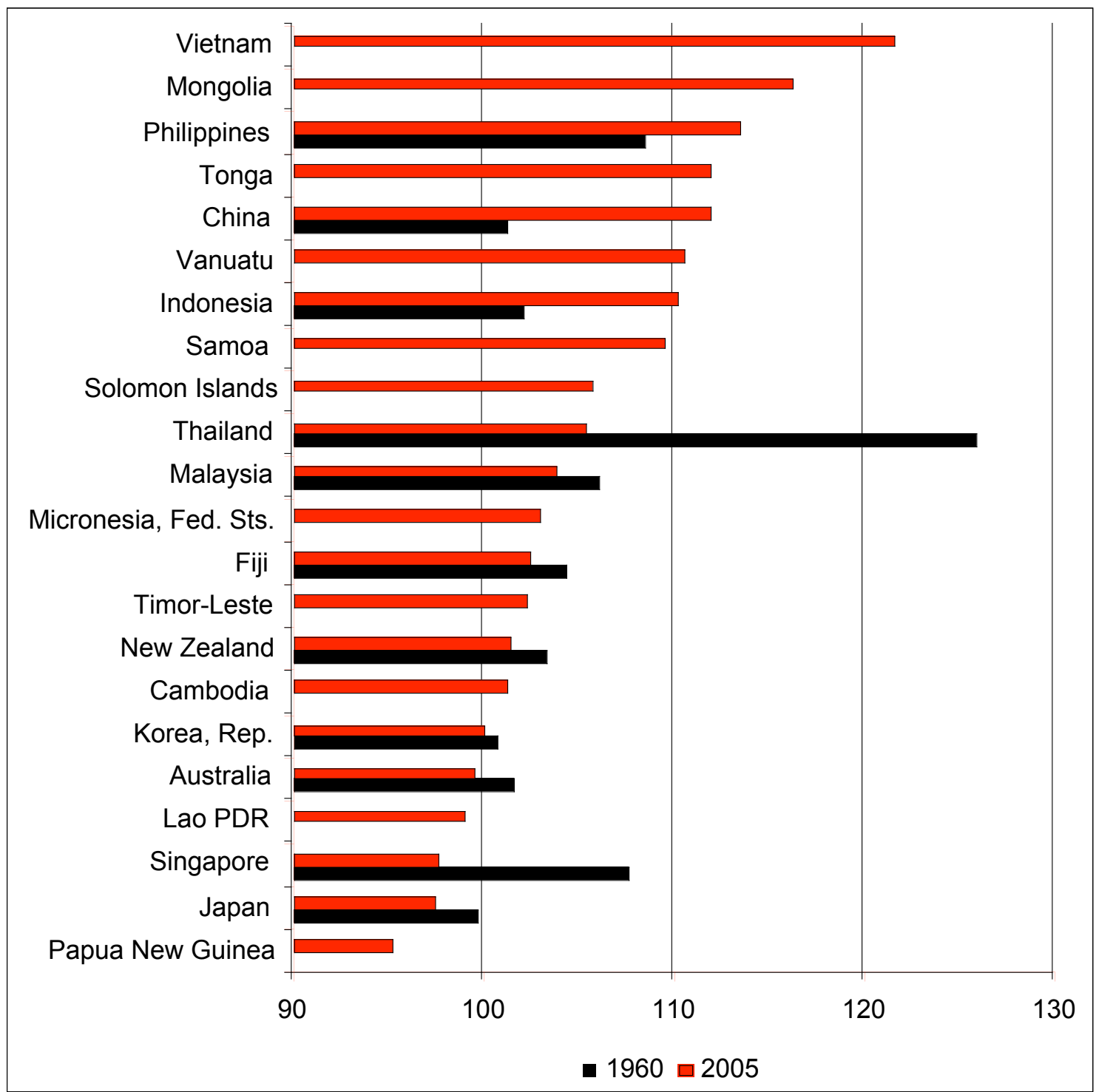


Figure 5: Life Expectancy versus Income Growth for an East Asian Sample 19602005

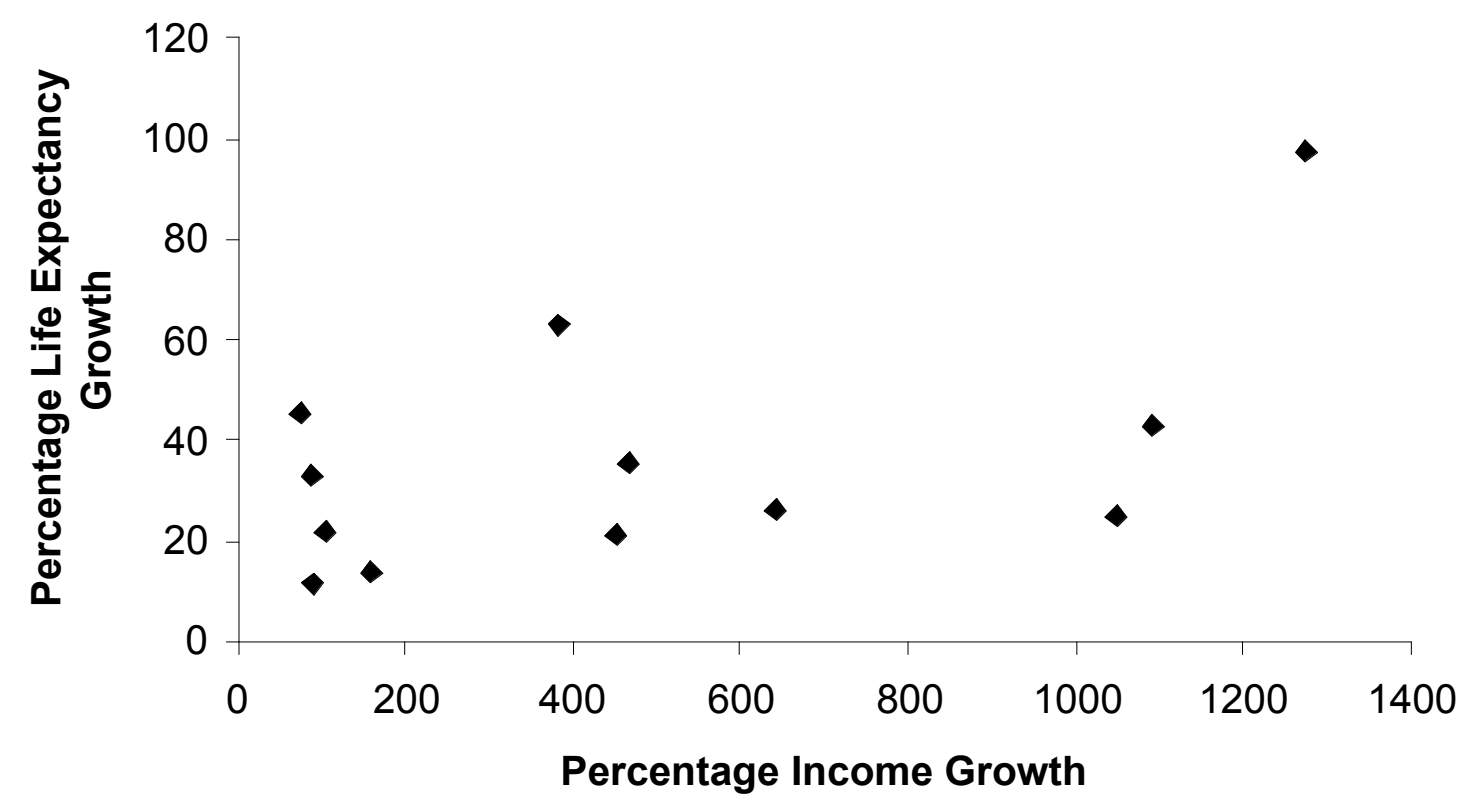

Figure 6: Infant Mortality per 1,000 Live Births 1960-2000

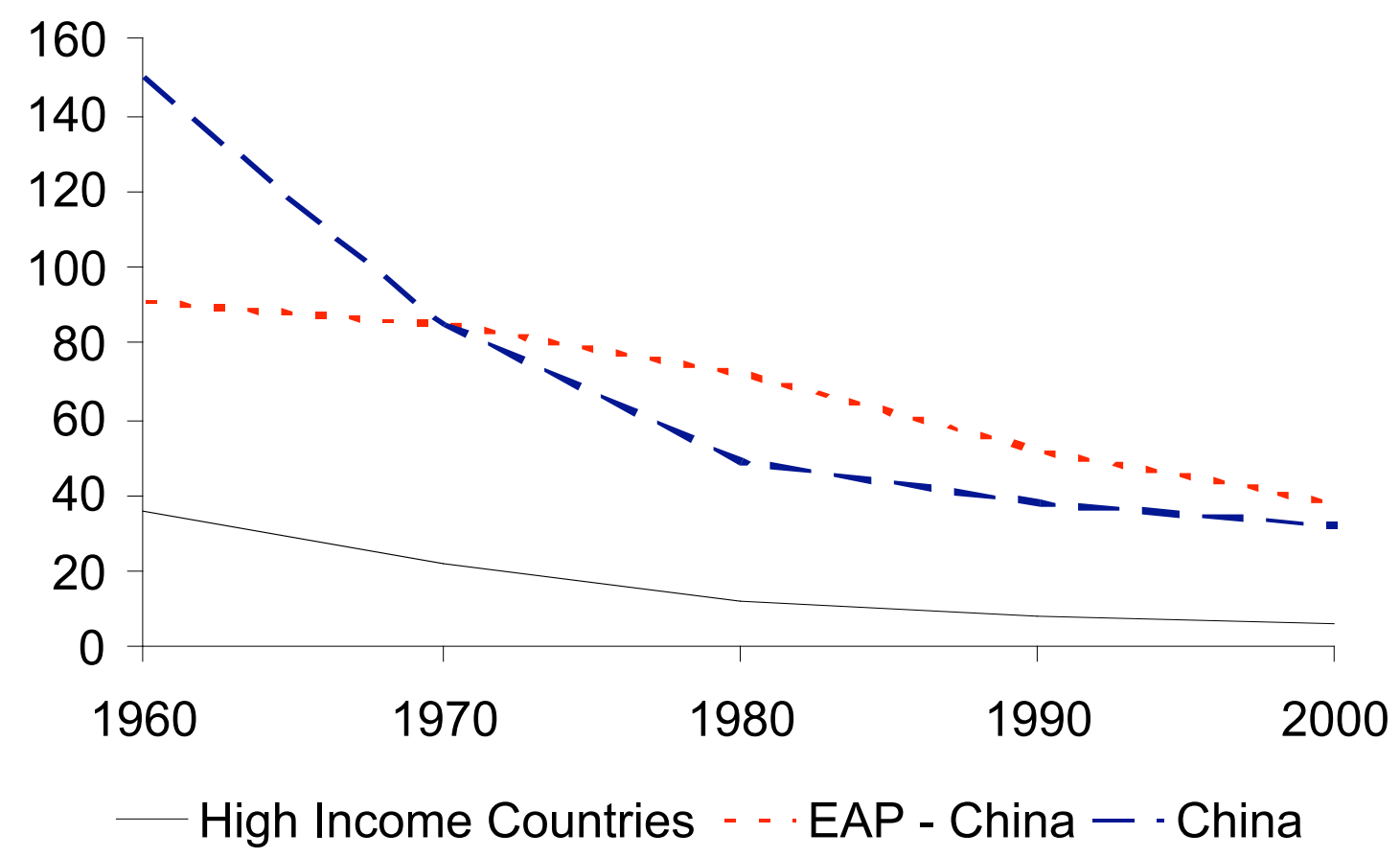




\section{Bibliography}

Boone P. and Z. Zhan (2006) Lowering Child Mortality in Poor Countries: The Power of Knowledgeable Parents, CEP Discussion Papers DP 0751.

Chakraborty, S., C. Papageorgiou and F. Sebastian, (2005) Diseases and Development Stanford CDDRL Working Paper 49.

Chen, Z. D. Eastwood and S. Yen (2007) A Decade's Story of Childhood Malnutrition Inequality in China: Where You Live Does Matter China Economic Review 18 139-154.

Clemens, Michael (2004). The Long Walk to School: International education goals in historical perspective, Working Paper 37, Center for Global Development, Washington, DC.

Cornia, G. and L. Menchini (2005) The Pace and Distribution of Health Improvements During the Last 40 Years: Some Preliminary Results, paper presented at the UNDPFrench government sponsored 'Forum on Human Development' Paris, 17-19 January.

Dearden, K., L. Pritchett and J. Brown (2003) Learning from Neighbors: Social Learning About Child Feeding During Diarrheal Episodes, mimeo, Kennedy School Harvard University.

Deaton, A. (2006) Global Patterns of Income and Health: Facts, Interpretations, and Policies, NBER Working Paper 12735.

Easterlin, R (1995) Industrial Revolution and Mortality Revolution: Two of a Kind? Journal of Evolutionary Economics 5: 393-408.

Felipe, Jesus, (1999) Total Factor Productivity in East Asia: A Critical Survey The Journal of Development Studies, Vol. 35, No. 4.

Filmer, D. J. Hammer and L. Pritchett (1997) Health Policy in Poor Countries: Weak Links in the Chain, World Bank Policy Research Working Paper 1874.

Filmer, Deon (2004). School Availability and School Participation in 21 developing Countries, World Bank Policy Research Working Paper 3340.

Fukuda, Y., K. Nakamura and T. Takano (2004) Increased Excess Deaths in Urban Areas: Quantification of Geographical Variation in Mortality in Japan, 1973-1998, Health Policy 68 233-44.

Johansson, S. and C. Mosk (1987) Exposure, Resistance and Life Expectancy: Disease and Death During the Economic Development of Japan 1900-1960 Population Studies 41, 207-235.

Kenny (2007) There's More to Life than Money: Exploring the Levels/Growth Paradox in Income and Health, mimeo, World Bank.

Kenny, A. and C. Kenny (2006) Life, Liberty and the Pursuit of Utility: Happiness in Philosophical and Economic Thought London: Imprint Academic.

Kenny, C (2005) Why Are We So Worried About Income? Nearly Everything That Matters is Converging World Development 33(1):1-19. 
Korenromp, E., F. Arnold, B. Williams, B. Nahlen and R. Snow (2004) Monitoring Trends in Under-5 Mortality Rates Through National Birth History Surveys International Journal of Epidemiology 33 1293-1301.

Lee, M. P. (2006) Widening Gap of Educational Opportunity? A Longitudinal Study of Educational Inequality in China, UNU-WIDER research paper 2006/66.

Leigh, A. and C. Jencks (2007) Inequality and Mortality: Long-Run Evidence from a Panel of Countries Journal of Health Economics 26 1-24

Liu, Y., W. Hsiao and K. Eggleston (1999) Equity in Health and Health Care: the Chinese Experience Social Science and Medicine 49 1349-1356.

Loevinsohn B. and A. Harding (2005) Buying results? Contracting for health service delivery in developing countries Lancet 2005; 366: 676-81

McGuire, J (2005) Basic Health Provision and Under-5 Mortality: A Cross-National Study of Developing Countries, World Development 34, 3.

Pritchett, Lant, and Larry Summers (1996). Wealthier is Healthier, Journal of Human Resources. 31, 4: 842-68.

Ranis, G. and F. Stewart (2001) Growth and Human Development: Comparative Latin American Experience The Developing Economies XXXiX-4 333-65.

World Bank (2007) World Development Indicators Washington DC: World Bank

Yusuf, S. and J. Stiglitz (eds) (2001) Rethinking the East Asian Miracle Washington DC, World Bank

Zhang, J. and J. Zhang (2005) The Effect of Life Expectancy on Fertility, Saving, Schooling and Economic Growth: Theory and Evidence Scandinavian Journal of Economics 107, 1. 
${ }^{\mathrm{i}}$ Senior Economist, the World Bank (ckenny@,worldbank.org, 1818 H St NW, Washington DC, 20007 USA). This paper was written in a personal capacity and the opinions reflect those of the author, not necessarily the World Bank, its Executive Directors or the Countries that they represent. Thanks for some very useful comments and suggestions to the two paper discussants (Konosuke Odaka and Rana Hasan), the editors of the Journal, and participants in the conference.

${ }^{\text {ii }}$ A search of Google Scholar conducted on 8/26/2007 entering the phrase "East Asian Miracle" returned 6,530 hits.

${ }^{\text {iii }}$ Again, this is from Google Scholar.

${ }^{\text {iv }}$ The picture was slightly less positive for infant and child mortality. Having said that, infant and child survival (the inverse measure) suggested strong evidence of convergence, suggesting the world is converging towards a state where all children survive.

${ }^{v}$ Calculated from data in World Bank (2007).

${ }^{\text {vi }}$ For data in this table, the samples are as follows (subject to data availability): East Asian large countries are Australia, Cambodia, China, Indonesia, Japan, Korea, Dem. Rep., Korea, Rep., Lao PDR, Malaysia, Mongolia, Myanmar, Papua New Guinea, Philippines, Singapore, Thailand, Vietnam. The full East Asia sample also includes American Samoa, Brunei Darussalam, Fiji, Guam, Kiribati, Marshall Islands, Micronesia, Fed. Sts., New Caledonia, New Zealand, Northern Mariana Islands, Palau, Samoa, Solomon Islands, Timor-Leste, Tonga and Vanuatu.

vii Infant mortality and child mortality are both significant determinants of life expectancy. Furthermore, child mortality is often estimated from levels of infant mortality in the data and vice-verca, and life expectancy is often estimated from either infant or child mortality.

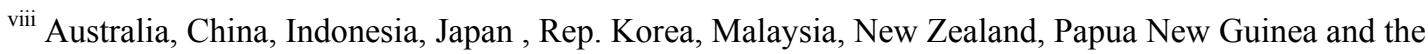
Philippines.

${ }^{\text {ix }}$ Available here: http://www.ggdc.net/maddison/

${ }^{\mathrm{x}}$ Similarly, Chen et. al. (2007) use household data from nine provinces in China to look at trends in income and malnutrition (stunting) $z$-scores, their data suggests that while average income considerably increased and stunting fell, the variation (as measured by the coefficient of variation) increased in both cases. Again, it appears that if the measure had been non-stunted children, the evidence would have been in favor of convergence -although see evidence of health divergence in China presented in the main text.

${ }^{x i}$ Rural areas saw lower death rates than urban areas -and rates that declined over time- suggesting that the historical pattern of Nineteenth-Century developed countries has reasserted itself at least in the case of Japan. At the same time, education, income and unemployment all have the expected impact.

${ }^{x i i}$ At the level of personal access to nutrition, in households with a child reported as malnourished in Brazil, China, and Russia 44, 23 and 57 percent respectively have an overweight member as well (Popkin, 2001). The cost of adequate nutrition appears to be dropping over time in poor countries. 
xiii Regarding infant mortality, the US reports deaths within the first 24 hours of birth as an infant death, and such deaths are frequently reported as stillbirths in other countries. Furthermore, medical advances in the US allow for a number of children to be born alive that would be stillborn in countries with less advanced medical systems. Nonetheless, other factors are clearly at work-African-American infant mortalities are more than twice the national average (see http://www.cdc.gov/nchs/fastats/pdf/nvsr50_15tb34.pdf). 